vo ideal, de servidores em cada orgão;

- propiciar a promocão, junto aos diversos órgãos, de programas de treinamento visando o desenvolvimento e especialização dos recur. sos humanos e

gerar informacōes de interesse dos órgãos vinculados ao CNPC, no sentldo de subsidlá-los na administraçāo de seu pessoal.

A implementacão e administracáo desse projeto ficou a cargo da Sedap e Seplan, que, por portaria delegou à Secretaria de Recursos Humanos e à Secretaria de Orcamento e Financas, que, em conjunto, estāo desenvolvendo o detalhamento do sistema, bem como as Instrucōes de procedimentos a serem cumpridas pelos órgãos.

Há de se ressaltar que o equipamento de processamento de dados a ser utilizado para montagem do Banco de Dados do CNPC, será o do IBGE por ser um computador de grande porte e com as características necessárias para suportar 0 grande número de informacōes.
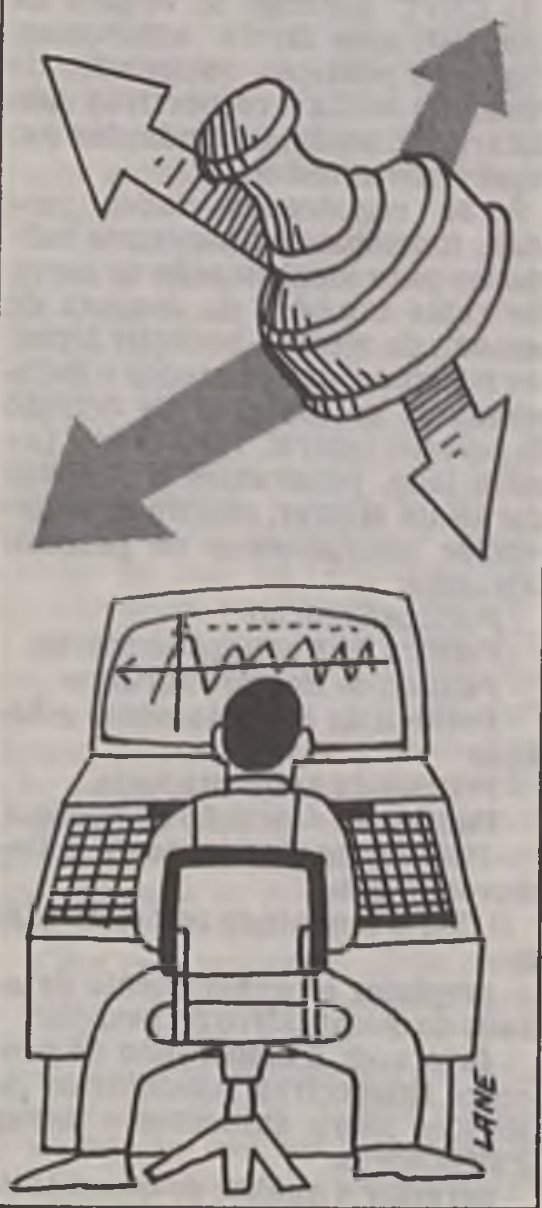

\title{
O computador torna a burocracia transparente
}

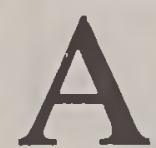

ntes de o presidente José Sarney lançar as bases para a Reforma Administrativa, já vinha funcionando, numa pequena sala do Ministério da Administração - agora transformado em Secretaria da Presidência - um dispositivo que abre caminho para lançar a burocracia brasileira na era da eletrônica. E o setor do Serviço Nacional de Protocolo, Senapro, que permite a localizaça e o andamento dos processos pela simples discagem do telefone 1515, acoplado a terminais de computador.

Graças a esse caçador eletrônico, atualmente operando nas faixas do próprio Ministério da Administracão c no da Fazenda, é possivel detectar, Ilão só o paradeiro, mas os enguiços que um processo sofre nos meandros da burocracia. É uma espécic de sentença de morte nas chamadas "gavetas", poroes dos servicos burocráticos onde a papelada mergulhava, às vezes para uma hibernação de longos anos.

- Um dos primeiros testes permiliu localizar um processo que estava cm Iramitação há nada menos de vinte c sete anos - revelou o ministro Aluizio Alves.

Os efeitos da implantação deste dispositivo são de ordens prática e psicológica, informa o engenheiro Adolfo José Ledebour, 37 anos, chefe da Coordenadoria de Comunicaçoes Administrativas, do Ministério da Administração, que é onde está situado o novo dispositivo.

Ledebour entende que, sabendose rastreado pelo faro dos computadores, o burocrata engavetador pensa duas vezes antes de reter um processo. Lamenta apenas que o público tenha custado a descobrir o novo serviço.

Mas os patrulheiros eletrônicos do Senapro nāo apenas rastreiam as andanças dos processos pelos caminhos das repartiçoes públicas, expli-

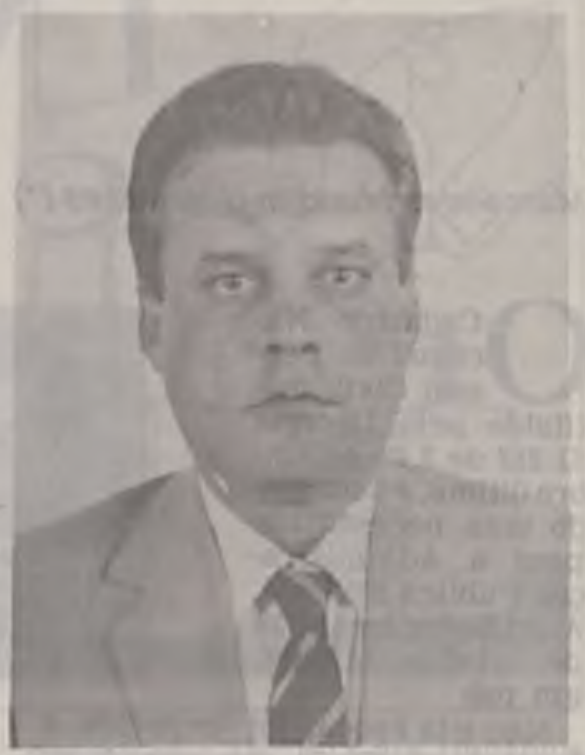

ca Ledebour, como revelam também o seu conteúdo. Em agosto último, cinco milhōes de processos já estavam cadastrados no sistema e, portanto, disponiveis para informação ao público.

Antes da introdução dessa metodologia, se alguém queria uma informação do Ministério da Fazenda tinha de comparecer pessoalmente às suas repartições. Agora, o contribuinte situado em qualquer ponto do Pais, onde exista um telefone, só precisa discar o 1515, antecedido do código DD (061), se estiver fora de Brasilia.

- Na realidade, o que nós fizemos - esclarece o diretor do Senapro - foi adaptar ao sistema telefone-computador e telexcomputador o que já vinha sendo feito manualmente.

\section{ATRASO, NUNCA MAIS}

Como os processos novos que estão chegando aos dois Ministérios são imediatamente cadastrados, não existe mais a possibilidade de descontrole daqui para a frente. 
Os boletins cadastrais, uma espécie de ficha dos processos, feitos no momento em que ele cai em um dos dois Ministérios, permite sua digitação no computador e, em consequêencia, sua localização onde ele se encontre a partir do momento em que deixa o Protocolo.

E o que é mais importante: são elaborados boletins de movimentação que são enviados para a central de computação do Serpro (Serviço Federal de Processamento de Dados), em Osasco, São Paulo. Cada passo dado pelo processo é imediatamente informado ao Serpro.

Sem a pretensão de reforma administrativa, na realidade a implantação do novo serviço acabou transformando em rotina um dos principios teóricos da Nova República - o da administração transparente, conforme frisou o ministro Aluizio Alves ao fazer seu lancamento.

- É a própria democratização do serviço públiço e da informação também - diz Adolfo José Ledebour. - O cidadão aciona o computador, por telefone ou telex, e tem instantaneamente a resposta ao serviço que está cobrando da reparti ção pública.

A perspectiva é levar o novo serviço aos demais Ministérios, tão logo esteja suficientemente aperfeiçoado e haja recursos humanos disponiveis para sua operação fora dos dois Ministérios onde está sendo empregado, atualmente.

Essa expansão pode ocorrer mesmo no bojo da Reforma Administrativa. O próprio Ledebour diz não ter "dúvida de que a informática será uma poderosa linha auxiliar da modernização do serviço público no Brasil".

O pessoal que está operando o sistema foi recrutado dentro do próprio Ministério da Administração. Foram selecionados servidores de bom nivel técnico-cultural e de boas maneiras no trato com o público.

O novo serviço não se limita a estabelecer o controle, pelo público, do andamento dos processos. Elabora também relatórios gerenciais, capazes de dizer quantos pareceres estāo pendentes sobre determinado assunto - abono-familia, por exemplo. Com isso, o gerente de setor terá uma avaliação periódica do desempenho de sua equipe e da papelada que está esperando providências.

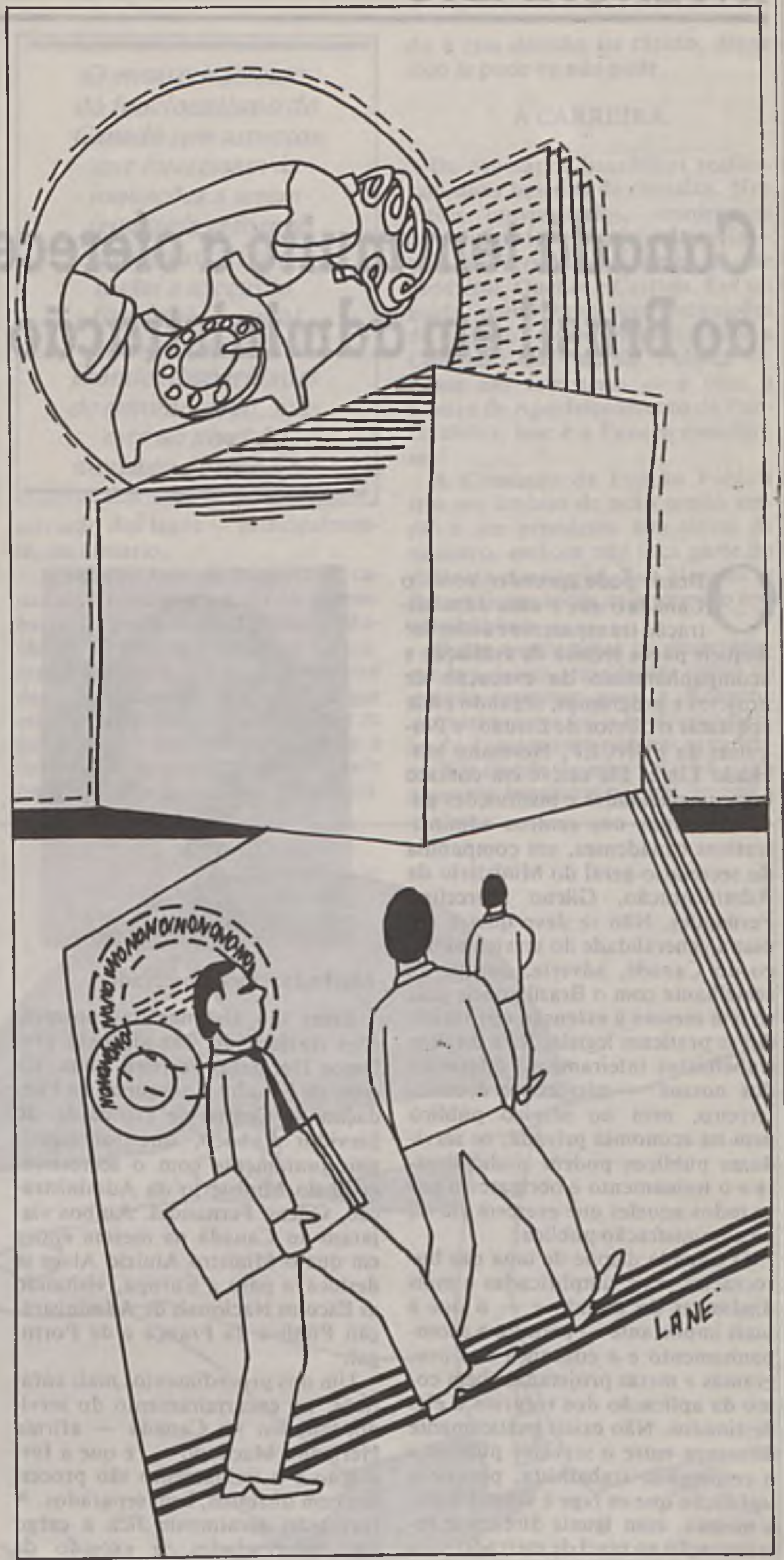

